\title{
On Local Scouring at Single Piers
}

\author{
António Heleno Cardoso ${ }^{1, *} \oplus$, Cristina Maria Sena Fael $2 \oplus$, Rui Miguel Madeira Lança $3 \oplus$ \\ ${ }^{1}$ Instituto Superior Técnico, Universidade de Lisboa, Lisboa, Portugal \\ 2 Universidade da Beira Interior, C-MADE, Covilhã, Portugal \\ ${ }^{3}$ Instituto Superior de Engenharia, Universidade do Algarve, Faro, Portugal \\ *Corresponding author: antonio.cardoso@tecnico.ulisboa.pt
}

Received: 29.06.2021 Accepted: 16.07.2021

\begin{abstract}
The paper mostly summarizes disperse contributions of the authors published during the last fifteen years on the scour depth at single piers. These contributions rely on unique experiments in the sense that they are systematically longer than most of those found in the literature. The characterization of the effects of flow intensity, relative sand size, flow shallowness, time and pier shape and alignment is significantly improved as compared with existing literature. Our contributions consist on refinements of the model suggested by the school of Auckland, initiated by Raudkivi and boosted by Melville and his students. A considerable number of empirical equations and charts expresses those contributions.
\end{abstract}

Keywords: Single piers; flow intensity; flow depth factor; sediment size factor; time factor; pier shape and alignment.

\section{Introduction}

Local scour around bridge piers and abutments is a frequent cause of partial failure or collapse of bridges. The reconstruction or rehabilitation of destroyed or damaged bridges frequently amounts to significant monetary costs. Above all, the casualties that occur in many of these disasters raise the societal claim for security. Enhanced security involves failure prevention, which in turn requires the accurate prediction of the scour depth or the adoption of proper mitigation scour countermeasures. In spite of the remarkable progresses registered since the mid-last century, scouring remains only a partly solved problem, due to the large number of variables involved in the processes and the inherent complexity of their phenomenological interactions.

The scope of this paper is scouring at single piers. Single piers are characterized by a unique cross-section along their main axes, assumed vertical. Local scouring at such single piers has been extensively studied. Research has been made mostly through experimentation. Early contributions of Chabert and Engeldinger (1956), Laursen and Toch (1956), Laursen (1963) or Shen et al. (1966) deserve to be mentioned, whereas one of the most comprehensive reviews on bridge scouring was offered by Melville and Coleman (2000).

For uniform flows in straight open channels, the maximum scour depth at a given moment, $d_{s}$, was shown to be described through the following parametric equation (see Fael (2007)): 


$$
\Pi_{d_{s}}=\phi\left(\Pi_{d} ; \Pi_{U} ; \Pi_{D_{50}} ; \sigma_{D} ; s ; \Pi_{v} ; \Pi_{f} ; \Pi_{\theta} ; \Pi_{W} ; \Pi_{G} ; \Pi_{t}\right)
$$

where $\Pi$ stands for non-dimensional parameter, $\phi$ means "function of" and subscripts refer to the variables influencing scouring. These are, namely, $d=$ flow depth; $U=$ average approach flow velocity; $D_{50}=$ median grain size of the bed sediment; $v=$ kinematic water viscosity; $f=$ pier shape; $\theta=$ pier alignment; $W=$ channel width; $G=$ geometry of the channel cross-section. Non-dimensional parameters $\sigma_{D}$ and $s$ stand for, respectively, gradation coefficient and specific gravity of the bed sediment. The basic variables used to derive Eq. (1) were the characteristic length of the pier cross-section, $D_{p}$, the gravitational acceleration, $g$, and the water density, $\rho$.

$$
\Pi_{d_{s}}=\phi\left(\Pi_{d} ; \Pi_{U} ; \Pi_{D_{50}} ; \sigma_{D} ; \Pi_{v} ; \Pi_{f} ; \Pi_{\theta} ; \Pi_{t}\right)
$$

In this equation, it is assumed that the effect of flow contraction on scouring at single piers vanishes in wide channels and that the specific sediment gravity is practically invariant, notably for sand. It is also assumed that the rectangular cross-section is the reference shape of open channels.

According to Melville and Coleman (2000), the previous equation can be materialized for piers as follows:

$$
\prod_{d_{s}}=K_{d} K_{U} K_{D 50} K_{\sigma_{D}} K_{v} K_{f} K_{\theta} K_{t} \quad \text { with } \quad \prod_{d_{s}}=\frac{d_{s}}{D_{p}} \quad \text { or } \quad \prod_{d_{s}}=\frac{d_{s}}{d}
$$

It should be noted here that $K_{d}$ refers to the effect of the relative flow depth or flow shallowness, $\Pi_{d}=d / D_{p} ; K_{U}$ accounts for the effect of flow intensity, $\Pi_{U}=U / U_{c}\left(U_{c}=\right.$ critical velocity of beginning of sediment motion); $K_{D 50}$ reflects the effect of relative sediment size or sediment coarseness, $\Pi_{D 50}=D_{p} / D_{50} ; K \sigma_{D}$ refers to the armoring effect (which mostly depends on $\left.\sigma_{D}\right) ; K_{v}$ accounts for the effect of fluid viscosity as captured through any form of the Reynolds number, e.g., $\Pi_{v}=u_{*} D_{50} / v\left(u_{*}=\right.$ friction velocity); $K_{f}$ and $K_{\theta}$ attend, respectively, to the effects of shape and alignment of the pier; and $K_{t}$ varies with the non-dimensional time, $\Pi_{t}=$ $U t / D_{p}$.

In the last fifteen years, we have revisited local scouring at single piers inserted in channel beds composed of practically uniform $\left(\sigma_{D}<1.5 ; K \sigma_{D}=1.0\right)$ non-ripple forming sand $\left(D_{50}>0.6\right.$ $\mathrm{mm}$ ). Under these conditions, we have indeed contributed to the enhanced characterization of Eq. (3). This paper reviews those contributions, synthetizing mostly the works of Lança et al. (2010), Simarro et al. (2011), Lança et al. (2013) and Fael et al. (2016). It does not cover the effects of water viscosity, bed armoring (due to the wide granular distribution of the bed material) or ripple forming bed material $\left(D_{50} \leq 0.6 \mathrm{~mm}\right)$ since we performed only a very limited number of experiments on these effects. The effect of viscosity can indeed be anticipated to be negligible since the flow field around obstacles tends to be rough turbulent, irrespective of the approach flow regime (smooth, transitional or rough).

Prior to addressing those contributions, we include a short description of the experimental facilities and granular materials used in the studies, as reported by Fael et al. (2014), and assess the calculation of the equilibrium scour depth from scour depth time records. 


\section{Experimental Facilities and Granular Materials}

Three horizontal-bed flumes were used in the studies. Each flume included a central reach consisting of a rectangular recess box in the bed (Figure 1), where the piers were installed. The main features of the flumes are shown in Table 1 , where $W=$ flume width, $L=$ flume length, $l$ $=$ distance from flume entrance to the recess box, $\ell_{1}=$ length of bed recess box and $d_{r}=$ its depth (Figure 1).

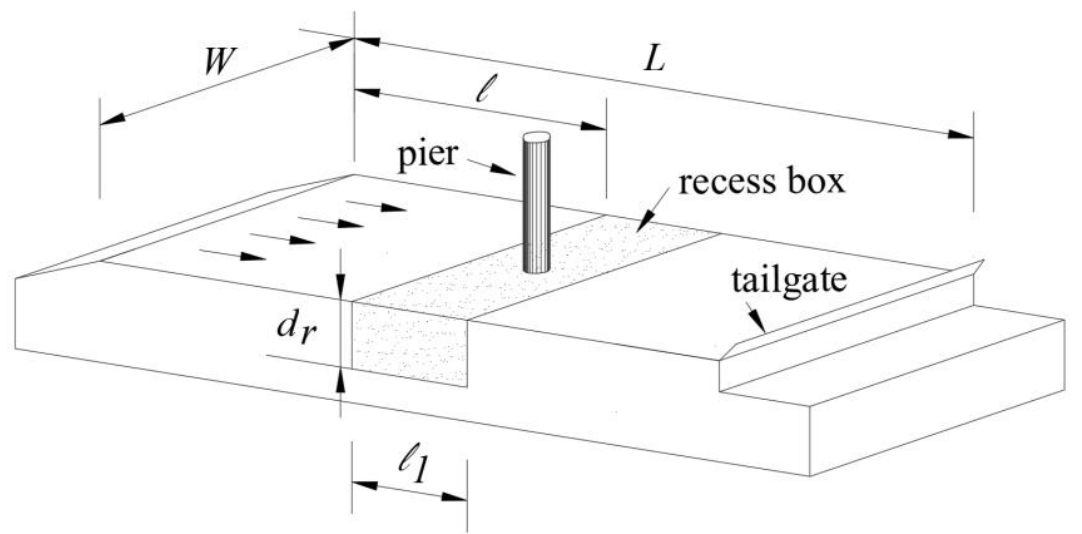

Figure 1. Sketch of the flumes

Table 1. Main features of the flumes

\begin{tabular}{lccccc}
\hline Flume & $W(\mathrm{~m})$ & $L(\mathrm{~m})$ & $\ell(\mathrm{m})$ & $\ell_{1}(\mathrm{~m})$ & $d_{r}(\mathrm{~m})$ \\
\hline $\mathrm{F}_{1}$ & 4.00 & 28.00 & 13.90 & 3.00 & 0.60 \\
$\mathrm{~F}_{2}$ & 0.83 & 12.70 & 5.00 & 3.10 & 0.35 \\
$\mathrm{~F}_{3}$ & 1.00 & 33.20 & 16.00 & 3.20 & 0.35 \\
\hline
\end{tabular}

Two natural quartz sands were used: sand $S_{1}$, defined by $D_{50}=1.28 \mathrm{~mm}$ and $\sigma_{D}=1.46$; sand $S_{2}$, defined by $D_{50}=0.86 \mathrm{~mm}$ and $\left.\sigma_{D}=1.36\right)$. Herein $\sigma_{D}=\left(D_{84.1} / D_{50}+D_{50} / D_{15.9}\right) / 2$ and $D_{50}=$ sand particle sieving diameter for which $50 \%$ are finer by weight. Both sands can be considered as uniform, since $\sigma_{D}<1.5$. The specific gravity was verified to be $s \approx 2.65$ in all cases.

Distinctive characteristics of the experiments were 1) the absence of contraction scour and wall effects and 2) their long duration. They typically lasted longer than 7 days, this way allowing the proper assessment of equilibrium scour depth. Another remarkable feature is the large number of experiments covering uncommon ranges of the relative sediment size or coarseness, $\Pi_{D 50}=D_{p} / D_{50}$.

\section{Experimental Equilibrium Scour Depth}

Local scouring occurs for two distinct sediment transport conditions: i) under clear-water, i.e., in the absence of sediment movement in the bed of the approach flow, which implies the bed shear stress to be smaller or, at most, equal to the critical bed shear stress of beginning of sediment motion; ii) under live-bed, i.e., when noticeable bed sediment movement occurs in the approach flow, meaning that the bed shear stress is larger than the critical bed shear stress. 
Conceptually, under clear-water, a scour hole is in equilibrium when the scour depth practically does no increase anymore, while under live-bed, a scour hole is in equilibrium when the timeaveraged amount of sediment leaving the scour hole equals the time-averaged amount of sediment that it captures from upstream. Starting from a flatbed, the time required to reach equilibrium scour depends on the state of sediment movement. For live-bed conditions, there is the simultaneous removal of grains originated from the scour hole and of those trapped by the same scour hole as they move downstream. The quantity of material that initially leaves the scour hole exceeds the quantity of material coming in and the scour depth increases. After a comparatively short time, both quantities tend to be equal. This state of equilibrium is known as dynamic equilibrium since the scour depth normally oscillates. The oscillations reflect the movement of bedforms - ripples, dunes, antidunes - that, in turn, induce periodical variations of the amount of sediments falling into the scour hole. In this context, it is pertinent to define the maximum scour depth, $d_{s m}$, as the sum of the average equilibrium scour depth, $d_{s e}$ with a value that depends on the semi-amplitude of bedforms.

For clear-water flow conditions, the increase of scour depth induces the continuous reduction of bed shear stress inside the scour hole until it becomes conceptually insufficient to transport sediment particles downstream. As scouring progresses, the scour rate decreases. The equilibrium depth is reached asymptotically and equilibrium is usually said to be static, in contrast with the live-bed case. It should be noticed here that, though the most frequent scour disasters occur under live-bed conditions associated with floods, scour due to long-lasting clear-water flows can originate slightly deeper scour holes.

The scour depth has classically been assumed to evolve in three phases, particularly in the clear -water flow case. These phases are i) the initial phase, where scour depth increases very quickly; ii) the principal phase, where the scour hole increases in depth and plan extent at a progressively decreasing rate; iii) the equilibrium phase, where the scour depth is assumed to stop increasing.

Until to the beginning of the present millennium, most studies assumed the existence of a finite time to reach equilibrium, both for clear-water and live-bed conditions. Many research works, including those of Cardoso and Bettess (1999), Fael et al. (2006) or Cardoso and Fael (2010), adopted this concept. At the dawn of the XXI century, Oliveto and Hager $(2002 ; 2005)$ stated that "end scour as the equilibrium state between the vortical agents and the resistance of sediments to be scoured does not normally exist", in disagreement with previous research works. Although there is no evidence supporting the inexistence of end scour, we recognize that the probability of occurrence of a sufficiently strong turbulent event capable of entraining bed grains is never null. Thus, it can be assumed that the mentioned probability decreases as scouring progresses, the scour depth evolving to a finite equilibrium value.

In other words, time to equilibrium can be conceived as infinity (notably, under clear-water flow conditions) although the equilibrium scour depth is indeed finite. Under these assumptions, the equilibrium scour depth of each experiment was derived by adjusting the polynomial equation,

$$
d_{s}=p_{1}\left(1-\frac{1}{1+p_{1} p_{2} t}\right)+p_{3}\left(1-\frac{1}{1+p_{3} p_{4} t}\right)+p_{5}\left(1-\frac{1}{1+p_{5} p_{6} t}\right)
$$

to the recorded time evolution of the scour depth. Parameters $p_{1}$ to $p_{6}$ were obtained through regression analysis and the equilibrium scour depth was calculated as $d_{s e}=p_{1}+p_{3}+p_{5}$ for $t=$ $\infty$. The above polynomial was suggested by Lança et al. (2010) as an improvement of a similar proposal by Bertoldi and Jones (1998). Lança et al. (2010) have shown that the method leads to 
practically invariant results for $d_{s e}$ as soon as experiments last for at least 7 days, which applies to the present experimental data.

\section{Flow Intensity Factor}

Referring to Eq. (3), let us consider that scouring occurs in a uniform flow on a straight, wide and rectangular open channel. Assuming also that i) the bed material is uniform $\left(K \sigma_{D}=1.0\right)$; ii) the pier is a cylinder $\left(K_{\theta}=K_{f}=1.0\right)$; iii) viscosity does not play a significant role on scouring $\left(K_{v}=1.0\right)$; iv) the scouring process has sufficiently approached the equilibrium stage $\left(K_{t}=1.0\right)$; v) $K_{D 50}=$ const., Eq. (3) comes

$$
\Pi_{d_{s e}}=\varphi\left(\Pi_{d} ; \Pi_{U}\right) \quad \text { with } \quad \prod_{d_{s e}}=\frac{d_{s e}}{D_{p}} \quad \text { or } \quad \Pi_{d_{s e}}=\frac{d_{s e}}{d}
$$

where $d_{s e}$ stands for equilibrium scour depth. For slender cylindrical piers, when the average approach velocity, $U$, reaches a value of the order of $0.5 U_{c}$ (Chabert and Engeldinger, 1956; Hanco, 1971), the flow structure around the pier induces local bed shear stresses that promote the beginning of grains motion, i.e., the initiation of the scour process (see Figure 2) although there is no sediment transport in the approach channel. To a given value of the approach flow velocity in the range $\approx 0.5 U_{c}<U<U_{c}$ corresponds one single value of the equilibrium scour depth, $d_{s e}$, as soon as $\Pi_{d}=d / D_{p}$ remains constant. The scour depth, $d_{s e}$ increases linearly with $U / U_{c}$ until it reaches its maximum for $U=U_{c}\left(\Pi_{U}=1.0\right)$. Increasing further the velocity, the bed grains of the approach flow will move and dunes will develop in the bed. For $U>U_{c}$, the movement of dunes downstream feeds the scour hole with successive waves of bed material that the vortical system (horseshow vortex plus wake vortices) keeps removing from the scour hole, this way reducing its capacity to erode the original bed. Through this mechanism, dunes tend to induce a small decrease of $d_{s e}$ as $U$ increases in the range $U_{c}<U<\approx 2 U_{c}\left(1<\Pi_{U}<\approx 2\right)$. A minimum of the equilibrium scour depth occurs for $U \approx 2 U_{c}$. For approach flow velocities in the range $\approx 2 U_{c}<U<\approx 4 U_{c}$, dunes become longer and their upstream slope become milder as flow velocity increases. The scouring process will be influenced by the arrival of other dunes with lower height and volume; the vortical system tends to be increasingly able to move the incoming sediments downstream. Consequently, the equilibrium scour depth increases again gradually with the approach flow velocity. A new maximum of $d_{s e}$ is reached for $U \approx 4 U_{c}\left(\Pi_{U} \approx\right.$ 4). This maximum is of the order of the one observed for $U=U_{c}$ but it occurs for the upperregime flat bed. For velocities higher than $\approx 4 U_{c}$, antidunes normally develop, and the scour depth tends to decrease again for the same reasons as those why the occurrence of dunes also decreases the equilibrium scour depth.

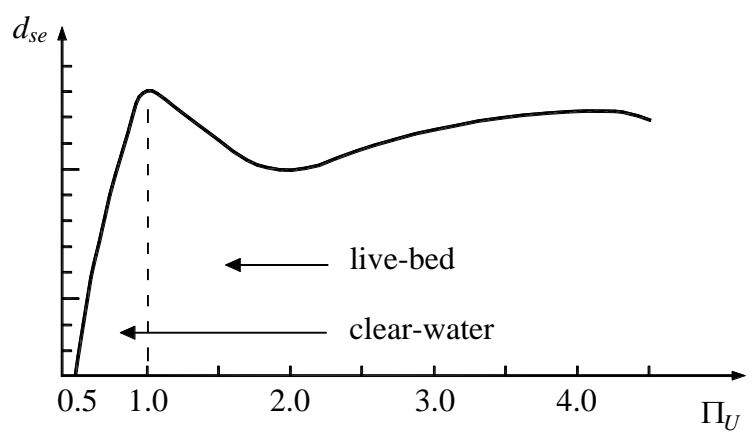

Figure 2. Typical variation of $d_{s e}$ with $U$ for comparatively coarse uniform bed sediment (adapted from Breusers and Raudkivi (1991)) 
It should be emphasized here that the condition of scour inception - given as $U / U_{c}=0.5$ and meaning that the critical value of the flow intensity for scour inception would be $\Pi_{U i}=0.5$ has not been consensual. For instance, Chiew (1995) indicated $\Pi_{u i}=0.3$, Melville $(1992,1997)$ suggested charts according to which $\Pi_{U i}=0$ and Hager and Oliveto (2002) proposed an equation to calculate $\Pi_{U i}$ as a function of the flow blockage.

In view of the lack of consensus, Fael et al. (2006) investigated the scour inception at vertical wall abutments by performing 31 long lasting (more than 7 days) experiments with sand S1 in the flume $\mathrm{F}_{1}$. Abutments' length, $\ell_{a}$, varied in the range $0.64 \mathrm{~m}<\ell_{a}<1.86 \mathrm{~m}$, the flow depth was kept practically constant $(\approx 0.06 \leq d \leq \approx 0.07 \mathrm{~m})$, the relative abutment length, $1 / \Pi_{d}=\ell_{a} / d$, spanned from 8.9 to 30.1 , the flow intensity covered the range $\approx 0.4<\Pi_{U}<\approx 1.0$ and wall effects and contraction scour were absent. Fael et al. (2006) also selected 25 experiments from the literature, covering lower values of $\ell_{a} / d$, between 2.0 and 17.4, and $\approx 0.6<\Pi_{U}<\approx 1.0$. From the data collected, Fael et al. (2006) concluded that the scour inception at vertical wall abutments is defined by

$$
\Pi_{U i}=\frac{1}{1+0.402\left(\ell_{a} / d\right)^{0.648}}
$$

Since abutments can be conceptually regarded as half-width piers, meaning that they mimic piers with $D_{p}=2 \ell_{a}$, the previous equation can be written as

$$
\Pi_{U i}=\frac{1}{1+0.257\left(D_{p} / d\right)^{0.648}}
$$

Eq(s). (6) and (7) are plotted in Figure 3 together with the equation suggested by Hager and Oliveto (2002). In this figure, $\ell_{O}$ stands for pier width, $D_{p}$, or abutment length, $\ell_{a}$, depending on the equation.

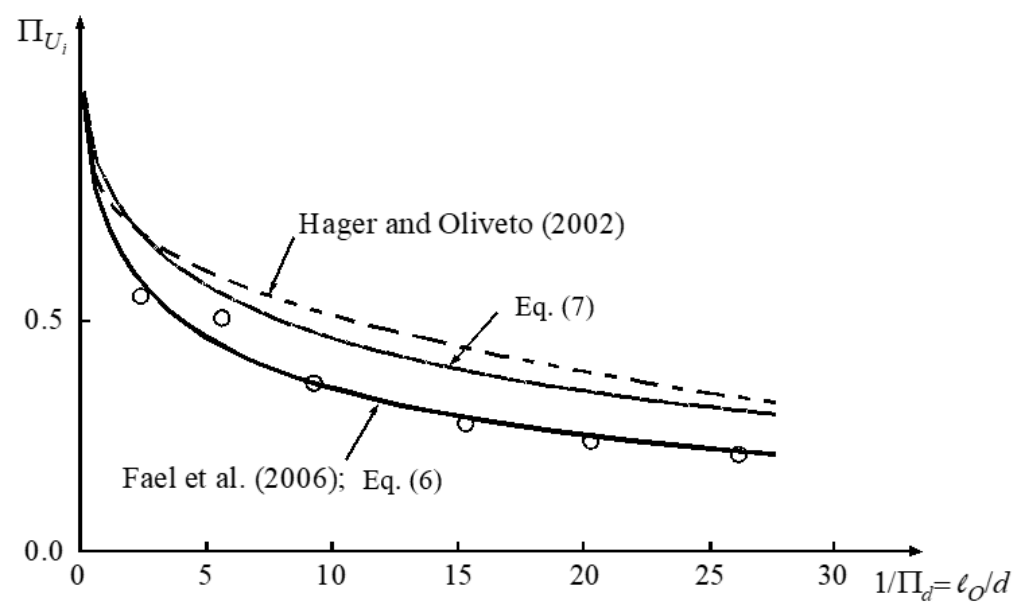

Figure 3. Variation of $\Pi_{U i}$ with $1 / \Pi_{d}$

Further assuming that the scour reduction occurring for $\Pi_{U} \approx 2.0$ is negligible, it can be concluded that $K_{U}$, defined as 


$$
K_{U}=\frac{d_{s e}\left(\text { for a given } \Pi_{U}\right)}{d_{s e}\left(\text { for } \Pi_{U}=1.0\right)}
$$

can be obtained as follows:

$$
K_{U}=\left\{\begin{array}{lr}
0 & \Pi_{U}<\Pi_{U i} \\
\frac{1}{1-\Pi_{U i}}\left(\Pi_{U}-\Pi_{U i}\right) & \Pi_{U i} \leq \Pi_{U}<1 \\
1 & \Pi_{U} \geq 1
\end{array}\right.
$$

This equation reflects the influence of $\Pi_{U}$ and $\Pi_{d}$ - trough $\Pi_{U i}-$ on $K_{U}$. It compares with other contributions according to Figure 4.

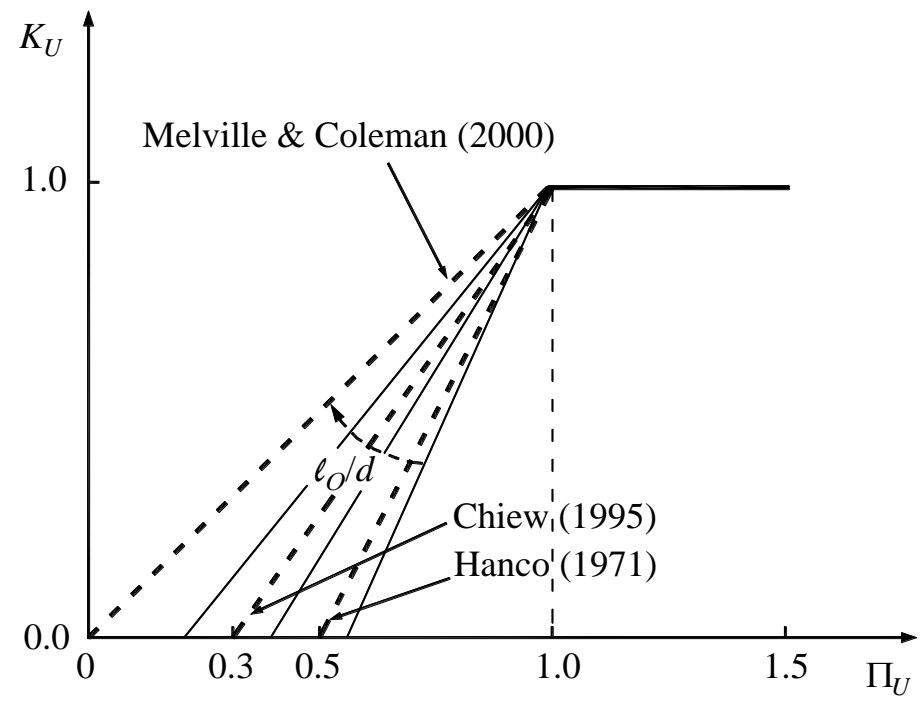

Figure 4. Variation of $K_{U}$ with $\Pi_{U}$

\section{Effects of Flow Depth and Sediment Size on the Equilibrium Scour Depth}

Resuming the scenario of rough turbulent uniform flows on uniform non-ripple forming sandbeds in straight, very wide, rectangular open channels and also considering constant values of flow intensity, $\Pi_{U}$, Eq. (3) reads

$$
\Pi_{d_{S}}=K_{d} K_{D_{50}} K_{f} K_{\theta} K_{t}
$$

The equilibrium scour depth - where $\Pi_{d s}=\Pi_{d s e}$ - at cylindrical piers $\left(K_{f}=K_{\theta}=1.0\right)$ can be described as

$$
\Pi_{d_{s e}}=K_{d} K_{D_{50}}
$$

It is unanimously recognized that the relative approach flow depth, $\Pi_{d}=d / D_{p}$, is a key parameter of the scour process. On the contrary, many authors (e.g. Ettema (1980), Melville 
and Chiew (1999)) have successively assumed that the normalized equilibrium scour depth, $\Pi_{d s e}=d_{s e} / D_{p}$ or $\Pi_{d s e}=d_{s e} / d$ does not depend on the relative sediment size, $\Pi_{D 50}=D_{p} / D_{50}$, as soon as $\Pi_{D 50}>\approx 25-50$. Under this assumption, the equilibrium scour depth would be given as

$$
\frac{d_{s e}}{D_{p}}=\varphi\left(\frac{D_{p}}{d}\right) \quad \text { or } \quad \frac{d_{s e}}{d}=\varphi\left(\frac{D_{p}}{d}\right) \quad \text { or } \quad d_{s e}=\varphi\left(d ; D_{p}\right)
$$

Kandasamy (1989) collected scour data for piers and abutments corresponding to comparatively low values of $\Pi_{D 50}$. In the attempt to unify the analysis of both obstacle types, he used a common characteristic length, $\ell_{0}$, to represent the abutment length (assuming $D_{p}=2.3 \ell_{a}$ ) and the pier diameter. He obtained the $3 \mathrm{D}$ representation of the surface

$$
d_{s e}=\varphi\left(d ; \ell_{O}\right)
$$

included in Figure 5 for $\Pi_{U} \approx 1.0$, i.e., corresponding to the maxima scour depths. According to Kandasamy (1989), this surface can be divided into four zones. Zone 1 consists of the planar area defined by $d>b_{1} l_{0}$ (surface $\mathrm{OAB}$ ). In this zone, covering the domain of slender piers, the scour depth does not depend on the flow depth, meaning that

$$
d_{s e}=C_{1} \ell_{O}
$$

Zone 4 (surface ODE) would be a planar surface too, obeying the condition $\ell_{0}>b_{2} d$. According to Kandasamy (1989), it would apply to long abutments, for which the equilibrium scour depth is independent of the obstacle length and only depends on the flow depth $\left(d_{s e}=C_{2} d\right)$.

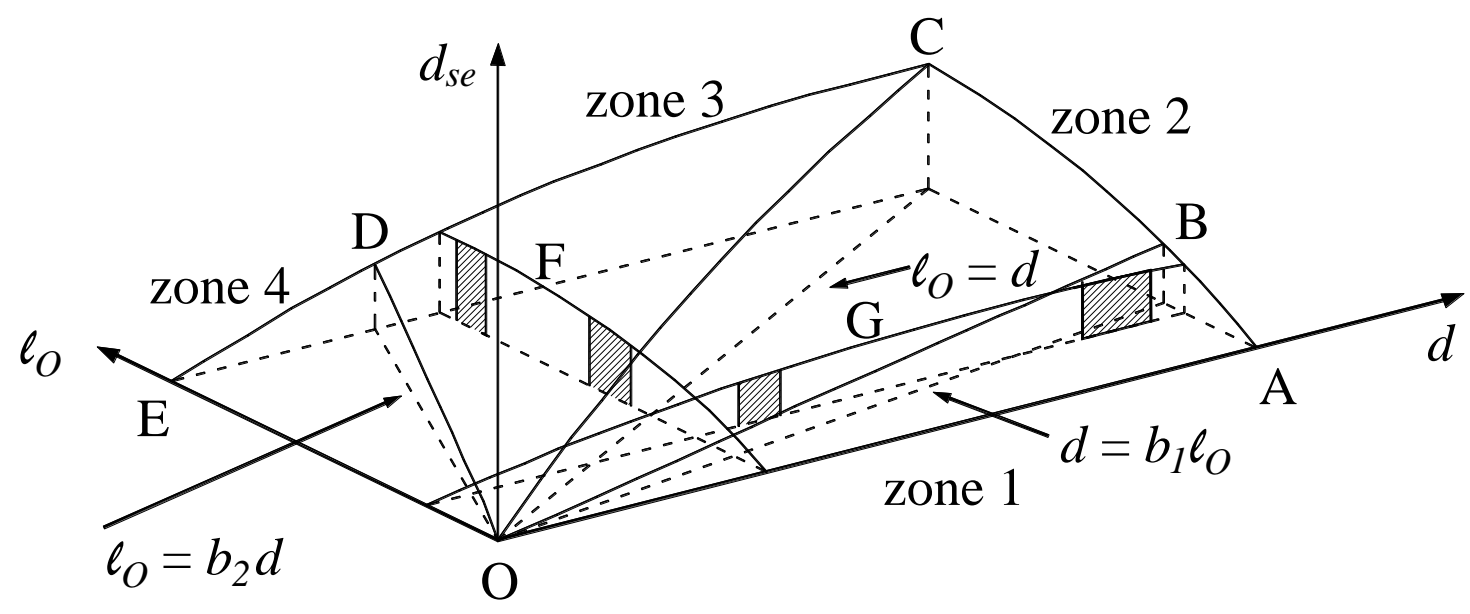

Figure 5. Shape of the function $d_{s e}=d_{s e}(d ; L)$ as defined by Kandasamy (1989)

Figure 5 includes curves $F$ and G, parallel to the axis of obstacle length and to the axis of flow depth, respectively. The curve F establishes the variation of $d_{s e}$ with $\ell_{0}$ for $d$ =const.; curve $\mathrm{G}$ 
establishes the variation of $d_{\text {se }}$ with $d$ for $\ell_{0}=$ const. Along curve $\mathrm{F}$, which intersects zones 1,2 and 3 , the scour depth increases strong and linearly with $\ell_{0}$ in zone 1 ; in zone 2 (where piers prevail), the increase slows down; this effect is even more pronounced in zone 3, corresponding to $\ell_{0}>d$. Had the curve crossed zone $4, d_{s e}$ would become constant and proportional to $d$. Qualitatively, curve G presents the same type of variation as curve F; it is obvious that the rate of increase of scour depth diminishes from zone 4 to zone 1 . To the right of the line $\mathrm{OB}, d_{s e}$ is independent of $d$ and becomes $C_{1} \ell_{O}$ (see Eq. (14)).

Several contributions can be found in the literature corresponding to specific forms of Eq. (13). One of the most widely spread was obtained by Melville $(1992 ; 1997)$ who suggested the following envelop curves for the calculation of equilibrium scour depth at cylindrical piers:

$$
\begin{aligned}
& \frac{d_{s e}}{D_{p}}=2.4 \quad \text { for } \quad D_{p} / d \leq 0.7\left(\Pi_{d} \geq 1.43\right) \\
& \frac{d_{s e}}{D_{p}}=2\left(\frac{D_{p}}{d}\right)^{0.5} \quad \text { for } \quad 0.7<D_{p} / d \leq 5\left(0.2 \leq \Pi_{d}<1.43\right) \\
& \frac{d_{s e}}{d}=4.5 \quad \text { for } \quad D_{p} / d>5\left(\Pi_{d}<0.2\right)
\end{aligned}
$$

It should be noticed here that the contribution of Melville $(1992 ; 1997)$ implicitly fixes $b_{1}=0.7$, $b_{2}=5, C_{1}=2.4$ and $C_{2}=4.5$.

The cancelation of the relative sediment coarseness effect - associated with $\Pi_{D 50}$ - assumed by Ettema (1980), Kandasamy (1989) and Melville (1992; 1997), among many others, was disputed by Sheppard et al. (2004) and Lee and Sturm (2009), according to whom $\Pi_{\text {dse }}$ decreases with increasing relative sediment size, particularly, for $\Pi_{D 50}>\approx 50$. In spite of the importance of this contribution, it did not sufficiently pervade the hydraulics community until to the present. Consequently, Lança et al. (2013) reassessed the influence of $\Pi_{D 50}$ on scouring. They performed thirty eight tests with sand $S_{2}$, lasting between 7 and 14 days on this effect, covering values of the relative sediment size in the range $58 \leq \Pi_{D 50} \leq 465$ and relative flow depth, $\Pi_{d}$, in the range $0.5 \leq \Pi_{d} \leq 5.0$, for flow intensity close to the condition of initiation of motion $\left(0.93 \leq \Pi_{U} \leq 1.04\right)$. In their tests, there were no significant wall as well as contraction scour effects.

The collected data allowed the characterization of Eq. (11). The values of $\Pi_{d s e}=d_{s e} / D_{p}$ are plotted against $\Pi_{D 50}$ in Figure 6. Data of six long duration clear-water experiments $\left(T_{d} \geq 6\right.$ days) by Sheppard et al. (2004) for $\Pi_{D 50}>500$ and $\Pi_{U}$ sufficiently close to 1.0 (0.85 to 1.21$)$ are also included. Figure 6 renders it clear that $\Pi_{D 50}$ influences $\Pi_{d s e}$ by decreasing the normalized scour depths as $\prod_{D 50}$ increases in the range of the study. 


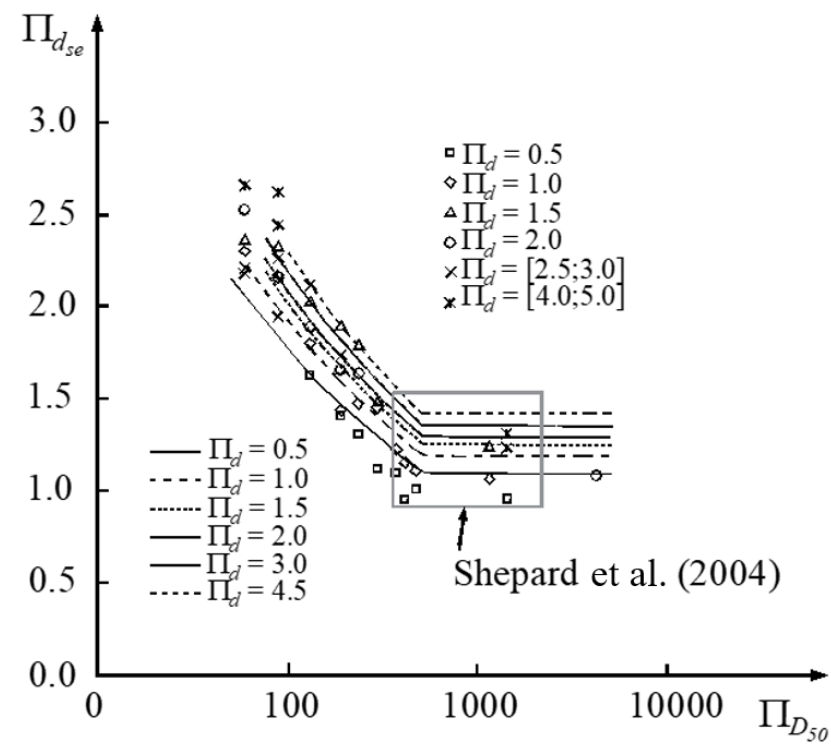

Figure 6. Effect of $\Pi_{D 50}$ and $\Pi_{d}$ on $\Pi_{d s e}$, Lança et al. (2013)

Lança et al. (2013) suggested the upper-bound predictor of the equilibrium scour depth given by Eq. (11), assuming that $K_{d}$ is the predictor of Melville (1997) slightly modified to read:

$$
K_{d}= \begin{cases}2.3\left(\Pi_{d}\right)^{1 / 3} & 0.50 \leq \Pi_{d} \leq 1.45 \\ 2.6 & \Pi_{d}>1.45\end{cases}
$$

and that $K_{D 50}$ is given by:

$$
K_{D 50}= \begin{cases}1.0 & 60<\Pi_{D 50} \leq 100 \\ 5.8\left(\Pi_{D 50}\right)^{-0.38} & 100<\Pi_{D 50} \leq 500 \\ 0.55 & \Pi_{D 50}>500\end{cases}
$$

In engineering practice, the use of $\mathrm{Eq}(\mathrm{s}) .(18)$ and (19) requires the application of appropriate multiplying factors - see Eq. (3) - to take into account the effects of flow intensity, viscosity, pier shape, pier alignment, gradation coefficient, flow contraction, channel cross-section shape and time. The effect of flow intensity was presented in section 4 . Sections 6 and 7 assess the time factor and the pier shape and alignment factors, respectively.

\section{Time Factor}

The data of Lança et al. (2010), covering time durations between 24.9 and 45.6 days, complemented with data of one 58.2 days-long experiment found in the literature, were reassessed by Simarro et al. (2011) who have shown that the exponential function suggested by Franzetti et al. (1982),

$$
K_{t}=\frac{d_{s}}{d_{s e}}=1-\exp \left[-a_{1} \prod_{t}^{a_{2}}\right] \quad \text { with } \quad \Pi_{t}=\frac{U t}{D_{p}}
$$

is a good predictor of the scour depth time evolution for clear-water flow conditions. The use of this equation requires the proper knowledge of $a_{1}$ and $a_{2}$, assuming that $d_{s e}$ is known. 
In the sequence of the assessment performed by Simarro et al. (2011), Lança et al. (2013) also revisited the proposal of Franzetti et al. (1982). Contrary to these authors, they have concluded that $a_{1}$ and $a_{2}$ are not constant. The multiplying coefficient $a_{1}$ varies in the range $0.005 \leq a_{1} \leq 0.080$, with an average value of 0.031 , whereas $a_{2}$ varies within the range $0.212 \leq a_{2} \leq 0.458$, with an average value of 0.311. Lança et al. (2013) have shown that $a_{1}$ and $a_{2}$ depend on $\Pi_{D 50}$ as follows:

$$
a_{1}=1.22\left(\Pi_{D 50}\right)^{-0.764} \quad a_{2}=0.09\left(\Pi_{D 50}\right)^{0.244}
$$

From the above, the model of Franzetti et al. (1982) for the prediction of scour depth time evolution can be applied to cylindrical piers in wide channels whose bed is composed of nonripple forming uniform sand whenever the approach flow velocity is close to the critical velocity of beginning of motion, i.e., for $\Pi_{U} \approx 1$.0. In this case, the time factor, $K_{t}$, reads as follows:

$$
K_{t}=1-\exp \left\{-1.22\left(\Pi_{D 50}\right)^{-0.764}\left[\Pi_{t}\right]^{0.09\left(\Pi_{D 50}\right)^{0.244}}\right\}
$$

Further research is needed to include the effect of $\Pi_{u}$ on $K_{t}$.

\section{Pier Shape and Alignment}

The pier shape multiplying factor $K_{f}$ of Eq. (3) is defined as the ratio between the scour depth at a pier with a given cross-section shape and the scour depth at the standard section-shape pier (usually the circular pier), all the other parameters kept constant. Likewise, the pier alignment or orientation factor, $K_{\theta}$, is defined as the ratio between the scour depth at a pier aligned with a given angle (angle of attack) towards the flow direction and the scour depth at an equal pier aligned with the flow direction (zero angle of attack), all the other parameters kept unchanged.

The effects of pier shape and alignment have received little attention since Laursen and Toch (1956). Yet, a number of pier shape factors, $K_{f}$, were suggested by different researchers. Richardson and Davis (2001) recommended the following expression that describes the values of $K_{\theta}$ obtained by Laursen and Toch (1956) for the particular case of rectangular piers:

$$
K_{\theta}=\left(\cos \theta+\ell_{p} / D_{p} \sin \theta\right)^{0.65}
$$

where $\ell_{p}$ stands for pier length and $D_{p}$ reads as pier width.

According to Richardson and Davis (2001), $K_{\theta}$ replaces the product $K_{f} K_{\theta}$ if the angle of attack, $\theta$, is larger than $5^{\circ}$ and $2<\ell_{p} / D_{p}<16$. This suggestion corroborates Laursen and Toch (1956) who found that the shape effect becomes negligible $\left(K_{f}=1.0\right)$ in the above domain.

Fael et al. (2016) extended the existing experimental evidence on $K_{f}$ and $K_{\theta}$ by performing fifty five tests with sand $S_{2}$ in Flume $F_{1}$ bisected longitudinally to render $W=2.0 \mathrm{~m}$. They tested rectangular square-nosed, rectangular round-nosed and oblong piers as well as zero-spacing (packed) pile-groups (see Figure 7) for skew angles $\theta=\left\{0^{\circ} ; 30^{\circ} ; 45^{\circ} ; 60^{\circ}\right.$ and $\left.90^{\circ}\right\}$ and aspect ratios $\ell_{p} / D_{p}=\{1.33 ; 2.0 ; 4.0\}$, i.e., extending down the lower limit of the experiments by Laursen and Toch (1956). 


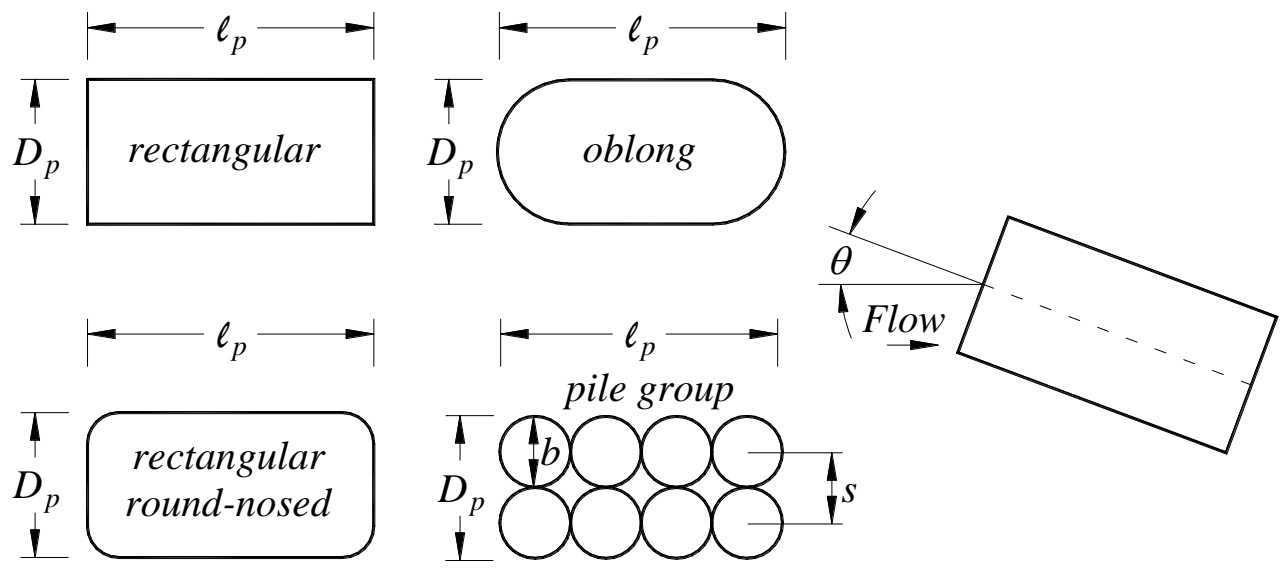

Figure 7. Tested pier shapes

Within their experimental domain, Fael et al. (2016) concluded that $i$ ) the shape factor is $K_{f}=1.0$, for rectangular round-nosed and oblong cross-section piers, and $K_{f}=1.2$, for rectangular square-nosed and pile-group cross-section piers; ii) the shape effect is nonnegligible at skewed piers, contrary to what is usually accepted, although the associated shape coefficients remain in the narrow range of 1.0 to 1.2; iii) Eq. (23) constitutes a good predictor of $K_{\theta}$ for $\ell_{p} / D_{p}=4.0$, whereas it is better described by

$$
K_{\theta}=\left\{\begin{array}{lll}
1+\frac{4 \theta}{1000} & \text { for } & \frac{\ell_{p}}{D_{p}}=1.33 \\
1+\frac{8 \theta}{1000} & \text { for } & \frac{\ell_{p}}{D_{p}}=2.00
\end{array}\right.
$$

In short, the scour depth at skewed piers depends on both shape and alignment as soon as $\ell_{p} / D_{p}<4.0$. This is relevant whenever equilibrium scour is to be calculated at piers whose crosssection is defined by small aspect ratios, $\ell_{p} / D_{p}$.

\section{Concluding Remarks}

This paper aims at reviewing contributions of the authors towards a more precise prediction of the equilibrium scour depth at single vertical piers. It covers the effects of $i$ ) flow intensity under clear-water flow conditions, $i$ ) flow depth and sediment size, iii) time evolution, and iv) alignment and cross-section pier shape. The paper also deals with the controversial concept and assessment of the equilibrium scour depth. Our contributions do not accrue from a new framework; they are rather a refinement of the model suggested by the school of Auckland, initiated by Raudkivi and boosted by Melville and his students. The enhanced predictive capacity associated to our works arises from precise equilibrium scour values properly estimated from unusually long experiments covering uncommonly high laboratory relative pier sizes.

Our most import contributions express K-factors of Eq. (3) and can be summarized as follows:

i) The critical value of flow intensity above which scouring is triggered is not a constant value but rather a function of the relative flow depth as given by Eq(s). (6) or (7).

ii) Flow intensity factor can be predicted by Eq. (9). 
iii) The relative sediment size factor is not constant for values of $\Pi_{D 50}$ above $25-50$, as it is frequently assumed, but it rather decreases in the range $100<\Pi_{D 50}<500$. It is described by Eq. (19).

iv) The effect of the relative flow depth or flow shallowness can be described by Eq. (18) instead of Eq(s). (15), (16) and (17).

v) The time factor is given by Eq. (22) for flow intensities close to 1.0, reflecting the effect of the relative grain size in the range $60<\Pi_{D 50}<500$.

vi) The shape effect is non-negligible at comparatively short skewed piers.

vii) Eq. (24) accounts for the alignment effect for small values of the pier cross-section aspect ratio.

It should be noted here that predictions of the improved Auckland's model (Eq. (3)) can be significantly smaller mostly due to the correction associated with the relative sediment size factor.

Another important contribution of the authors to the topic of local scouring is of instrumental nature and refers to the evaluation of the equilibrium scour depth in clear-water scour experiments. These should last for at least about one week and the issuing scour values be adjusted by the six parameters polynomial given by Eq. (4) (or a similar equation) to render the value of the scour depth at infinite time.

\section{Nomenclature}

$a_{1} \quad$ coefficient of the model of Franzetti et al. (1982)[-]

$a_{2} \quad$ coefficient of the model of Franzetti et al. (1982)[-]

$b_{1} \quad$ experimental cst. [-]

$b_{2} \quad$ experimental cst. [-]

$b \quad$ pier diameter in a pile group [m]

$C_{1} \quad$ experimental cst. [-]

$C_{2} \quad$ experimental cst. [-]

$d$ flow depth [m]

$D_{15.9}$ sand particle sieving diameter for which $15.9 \%$ are finer by weight $[\mathrm{m}]$

$D_{50} \quad$ sand particle sieving diameter for which $50 \%$ are finer by weight; median grain size of the bed sediment [m]

$D_{84.1}$ sand particle sieving diameter for which $84.1 \%$ are finer by weight [m]

$D_{p}$, characteristic length of the pier cross-section [m]

$d_{r} \quad$ depth of bed recess box $[\mathrm{m}]$

$d_{s} \quad$ scour depth [m]

$d_{s e} \quad$ equilibrium scour depth $[\mathrm{m}]$

$d_{s m} \quad$ maximum scour depth [m]

$f \quad$ pier shape [-]

G channel cross-section geometry [-]

$g$ gravitational acceleration [ $\left.\mathrm{ms}^{-2}\right]$

$K_{d}$ flow shallowness or relative flow depth factor [-]
$K_{D 50}$ relative sediment size factor or sediment coarseness factor [-]

$K_{f} \quad$ pier shape factor [-]

$K_{U} \quad$ flow intensity factor [-]

$K_{t} \quad$ time factor [-]

$K_{v} \quad$ fluid viscosity factor [-]

$K_{\theta} \quad$ pier alignment factor [-]

$K \sigma_{D}$ armoring factor [-]

$\ell$ distance from flume entrance to the recess box $[\mathrm{m}]$

$L \quad$ flume length [m]

$\ell_{1} \quad$ length of bed recess box [m]

$\ell_{a} \quad$ abutment length [m]

$\ell_{0} \quad$ obstacle length [m]

$\ell_{\mathrm{P}} \quad$ pier length $[\mathrm{m}]$

$p_{1}-p_{6}$ experimental constants [-]

$S \quad$ specific gravity of the bed sediment

$[-]$

$t \quad$ time $[\mathrm{s}]$

$U$ average approach flow velocity $\left[\mathrm{ms}^{-1}\right]$

$\mathcal{U}^{*} \quad$ friction velocity $\left[\mathrm{ms}^{-1}\right]$

$U_{c} \quad$ critical velocity of beginning of sediment motion $\left[\mathrm{ms}^{-1}\right]$

$W \quad$ channel width [-]

$\Pi \quad$ any non-dimensional parameter [-] 


\begin{tabular}{|c|c|}
\hline$\Pi_{d}=d / \ell_{a}$ and $\Pi_{d}=d / D_{p} \quad$ relative flow & $\begin{array}{ll}\Pi_{U i} & \text { scour inception parameter [-] } \\
\Pi_{U i} & \text { cross-section aspect ratio [-] }\end{array}$ \\
\hline $\begin{array}{l}\text { depth or flow shallowness [-] } \\
\prod_{d s} \quad \text { non-dimensional scour depth [-] }\end{array}$ & $\Pi_{v}=u_{*} D_{50} / v \quad$ particle Reynolds number [-] \\
\hline $\begin{array}{l}\Pi_{d s e}=d_{s e} / d \text { and } \Pi_{d s e}=d_{s e} / D_{p} \text { non- } \\
\text { dimensional equilibrium scour depth [-] }\end{array}$ & $\begin{array}{ll}\Pi_{\theta} & \text { alignment parameter [-] } \\
\phi & \text { function of [-] }\end{array}$ \\
\hline $\begin{array}{l}\Pi_{D 50}=D_{p} / D_{50} \text { relative sediment size or } \\
\text { coarseness [-] }\end{array}$ & $\begin{array}{l}\text { kinematic water viscosity }\left[\mathrm{m}^{2} \mathrm{~s}^{-1}\right] \\
\text { pier alignment }\left[{ }^{\circ}\right]\end{array}$ \\
\hline$\Pi_{f} \quad$ pier shape parameter $[-]$ & $\rho \quad$ water density $\left[\mathrm{kgm}^{-3}\right]$ \\
\hline$\Pi_{G} \quad$ channel cross-section parameter $[-]$ & $\sigma_{D}$ gradation coefficient of the bed \\
\hline
\end{tabular}

$\Pi_{U}=U / U_{c} \quad$ flow intensity [-]

\section{Author Statement}

The authors confirm contribution to the paper as follows: all authors have contributed equally to the study conception and design, analysis and interpretation of results, draft manuscript preparation. All authors reviewed the results and approved the final version of the manuscript.

\section{Conflict of Interest}

The authors declare no conflict of interest.

\section{References}

Bertoldi, D.A. \& Jones, J.S. (1998). Time to scour experiments as an indirect measure of stream power around bridge piers. Proceedings of the International Water Resources Engineering ‘98, Memphis, Tennessee, 264-269.

Breusers, H.N.C. \& Raudkivi, A.J. (1991). Scouring, Hydraulics Structures Design Manual. IAHR A.A. Balkema edt., Rotterdam.

Cardoso, A.H. \& Bettess, E. (1999). Time evolution and effect of channel geometry on local scour at bridge abutments. Journal of Hydraulics Engineering, 125(4), 388-399.

Cardoso, A.H. \& Fael, C.M.S. (2010). Time to equilibrium scour at vertical wall bridge abutments. ICE Journal on Water Management. 163(VM10), 509-513.

Chabert, J. \& Engeldinger, P. (1956). Etude des affouillements autor des piles de ponts. Lab. Natl. d'Hydraul., Chatou, France.

Chiew, Y.M. (1995). Mechanics of riprap failure at bridge piers. Journal of Hydraulic Engineering, 121(9), 635-643.

Ettema, R. (1980). Scour at bridge piers. Report No. 216, University of Auckland, Auckland, New Zealand.

Fael, C.M.S. (2007). Erosões localizadas junto de encontros de pontes e respectivas medidas de protecção. PhD thesis, University of Beira Interior, Covilhã, Portugal.

Fael, C.M.S., Simarro-Grande, G., Martín-Vide, J.P. \& Cardoso, A.H. (2006). Local scour at vertical-wall abutments under-clear water flow conditions. Water Resources Research. 42, W10408. 
Fael, C.M.S., Lança, R.M.M. \& Cardoso, A.H. (2016). Effect of pier shape and pier alignment on the equilibrium scour depth at single piers. International Journal of Sediment Research, 31(3), 244-250.

Fael, C.M.S, Lança, R.M.M., Couto, L. \& Cardoso, A.H. (2014). Local scour at single piers revisited, 3rd IAHR European Congress, Porto, April, paper 12.

Franzetti, S., Larcan, E. \& Mignosa, P. (1982). Influence of tests duration on the evaluation of ultimate scour around circular piers. Proc., Int. Conf. on the Hydraulic Modeling of Civil Engineering Structures, BHRA Fluid Engineering, England, 381-396.

Hager W.H. \& Oliveto, G. (2002). Shields' entrainment criterion in bridge piers. Journal of Hydraulic Engineering, 128(5), 538-542.

Hanco, S. (1971). Sur le calcul des affouillements locaux dans la zone de piles de pont, XIV Congrés de IAHR, Communication C36 aux, Paris.

Kandasamy, J.K. (1989). Abutment scour. Report n ${ }^{\circ}$ 458, School of Engineering, University of Auckland, Auckland, New Zealand.

Lança, R., Fael, C. \& Cardoso, A.H. (2010). Assessing equilibrium clear-water scour around single cylindrical piers. River Flow 2010, Dittrich, A. et al., eds., Bundesanstalt für Wasserbau, Germany, 1207-1213.

Lança, R., Fael, C., Maia, R., Pêgo, J. \& Cardoso, A.H. (2013). Clear-water scour at comparatively large cylindrical piers. Journal of Hydraulic Engineering, 139(11), 11171125.

Laursen, E.M. (1963). An analysis of relief bridge scour. J. Hydraulic Division Am Soc. Civ. Eng., 89(HY3), 93-118.

Laursen, E. \& Toch, A. (1956). Scour around bridge piers and abutments. Bulletin No. 4, Iowa Highway Research Board.

Lee, S., \& Sturm, T. (2009). Effect of sediment size scaling on physical modeling of bridge pier scour. Journal of Hydraulic Engineering, 135(10), 793-802.

Melville, B.W. (1992). Local scour at bridge abutments. Journal of Hydraulic Engineering, 184(4), 615-631.

Melville, B.W. (1997). Pier and abutment scour: integrated approach. Journal of Hydraulic Engineering, 123(2), 125-136.

Melville, B.W. \& Coleman, S.E. (2000). Bridge scour. Water Resources publications, LLC, CO.

Melville, B.W. \& Chiew, Y.M. (1999). Time scale for local scour at bridge piers. Journal of Hydraulic Engineering, 125(1), 59-65.

Oliveto, G. \& Hager, W.H. (2002). Temporal evolution of clear-water pier and abutment scour. Journal of Hydraulic Engineering, 128(9), 811-820.

Oliveto, G. \& Hager, W.H. (2005). Further results to time-dependent local scour at bridge elements. Journal of Hydraulic Engineering, 131(2), 97-105.

Richardson, E.V. \& Davis, S.R. (2001). Evaluating scour at bridges. Hydraulic Engineering Circular No. 18 (HEC-18). Rep. No. FHWA NHI 01-001, Federal Highway Administration, Washington, D.C.

Shen, H.W., Schneider, V.R. \& Karaki, S.S. (1966). Mechanics of local scour., U.S. Department of Commerce, National Bureau of Standards, Institute for Applied Technology, 1966. 
Sheppard, D.M., Odeh, M. \& Glasser, T. (2004). Large scale clear-water local pier scour experiments. Journal of Hydraulic Engineering, 130(10), 957-963.

Simarro, G., Fael, C. \& Cardoso, A.H. (2011). Estimating equilibrium scour depth at cylindrical piers in experimental studies. Journal of Hydraulic Engineering, 137(9), 1089-1093. 